\title{
A Naturally Occurring Enterotyphlocolitis Associated with Dual Infection by Clostridium piliforme and Enteropathogenic Attaching and Effacing Escherichia coli in Syrian
} Hamsters

\author{
TA Aboellail ${ }^{{ }^{*}}$, Naikare $\mathrm{HK}^{2}$, Mahapatra $\mathrm{D}^{2}$ \\ ${ }^{1}$ From the Veterinary Diagnostic Laboratories, Department of Microbiology, Immunology and Pathology, College of Veterinary Medicine \\ and Biomedical Sciences, Colorado State University, Fort Collins, CO, USA \\ 2 Texas A \& M Veterinary Medical Diagnostic Laboratory, Amarillo, TX, USA
}

* Corresponding author: Tawfik Aboellail, Veterinary Diagnostic Laboratories, Department of Microbiology, Immunology and Pathology, College of Veterinary Medicine and Biomedical Sciences, Colorado State University, 300 W. Drake Street, Fort Collins, CO 80523-1644, USA, Email: tawfik.aboellail@colostate.edu

Copyright: (c) 2013 Aboellail TA, et al. This is an open access article distributed under the Creative Commons Attribution License, which permits unrestricted use, distribution, and reproduction in any medium, provided the original work is properly cited.

\begin{abstract}
Three outbred weanling Syrian hamsters (Mesocricetus auratus) were submitted for necropsy after developing variably severe diarrhea and depression or dying unexpectedly shortly after shipping to a commercial pet store. Grossly, the three weanlings had thin-walled intestines that were distended with excessive amounts of turbid, yellowish-green fluid contents and friable mucosa, particularly in the ileum and cecum. Silver stain highlighted intralesional "stacks" of rod-shaped filamentous bacteria characteristic of Tyzzer's disease in both of the small and large intestines of all three animals. Additionally, the liver of one weanling No.1 contained multifocal pinpoint foci of necrosis throughout the hepatic parenchyma and milder necrotizing lesions in the myocardium. In the intestines of the three weanlings, colonies of gram negative plump bacilli scalloped the apical surface of ileal, cecal and colonic enterocytes containing Clostridium piliforme (C. piliforme) filamentous bacilli in their cytoplasm. Samples of fresh intestines and feces from the three weanlings plus the liver from the weanling \#1 demonstrated a 270-bp band specific to C. piliforme. Another 425-bp band specific to attaching and effacing Escherichia coli (AEEC) was identified in the intestines of the three hamsters. The PCR products were sequenced using $16 \mathrm{~S}$ ribosomal ribonucleic acid (rRNA) gene based primers revealing $98 \%$ sequence alignment and homology with sequences specific to $C$. piliforme. This article represents the first published cases of enterotyphlocolitis associated with dual natural infection by AEEC and C. piliforme.
\end{abstract}

Keywords: Attaching and effacing E. coli; C. piliforme; pathology; PCR; Syrian hamster; Tyzzer's disease 


\section{Introduction}

Transmissible enteritis in Syrian hamsters was first described in the seventies where the identity of the causative bacteria was uncertain but the intracellular bacteria were identified with Warthin-Starry stain and electron microscopy. The putative bacteria resembled Campylobacter species [1]. Non-hemolytic Escherichia coli and Campylobacter-like organisms were associated with a natural outbreak of enetrocolitis in a colony of breeding Syrian hamsters over a period of 2 years [2]. The enteropathogeneicity of E. coli isolated from moribund hamsters was proven in pathogenesis studies in intestinal loops from weanling but not adult hamsters [3].

Enteropathogenic Escherichia coli (EPEC) usually results in variably severe diarrhea in a wide range of hosts, including calves, dogs, hamsters, lambs, pigs, rabbits, deer, and humans $[4,5]$. The severity of the clinical disease in infected animals is attributed to a distinctive mechanism of bacterial colonization that is characterized by intimate bacterial adherence to the intestinal mucosa. Following the initial adherence of the bacteria to the apical surface of enterocytes, the attaching bacteria efface the microvilli and form pedestal-like structures beneath the adherent bacteria inciting attaching and effacing (A/E) lesions $[6,7]$. The ultrastructural changes typify these lesions are characterized by cytoskeletal rearrangements in the host enterocytes, in particular the recruitment of actin filaments beneath adherent bacteria [8]. The ability of AEEC to manipulate the host cytoskeleton is encoded by the chromosomal "locus of enterocyte effacement" (LEE) pathogenicity island, an essential virulence factor $[6,7,9,10]$. Another chromosomal gene, eaeA, encodes the protein intimin, which is an adhesin that is directly involved in the A/E activity [11-13]. A second adherence factor, the plasmid-encoded type 4 bundle-forming pilus (BFP) is also required for intestinal colonization [14,15]. Throughout A/E infection E. coli remain as extracellular pathogens only restricted to the mucosal surface $[16,17]$.
Pathogenesis of the diarrhea due to EPEC is complex and involves multiple mechanisms including: 1) malabsorption; 2) active secretory mechanism; 3) active alteration of ions across intestinal epithelial membranes; and 4) local inflammation associated by transmigration of neutrophils [16-19].

In contrast, C. piliforme, the causative agent of Tyzzer's disease, is an anaerobic, pleomorphic, obligate intracellular, Gram-variable though predominantly Gram negative, sporeforming, filamentous rod-shaped bacterium that is difficult to isolate in cell-free media [20]. On the basis of 16S RNA analysis, the organism has been assigned to the genus Clostridium that can cause natural infection in a wide variety of domestic, wild, and laboratory animals including hamsters [21-23]. Tyzzer's disease occurs among laboratory animals stressed by poor environmental conditions, overcrowding, and high temperature or may result from activation of latent infections, as is the case in muskrats [24]. The distal intestine, specifically the ileo-cecal-colic junction is the primary site of infection by $C$. piliforme where interleukin12 (IL-12) seems to play a key role in the pathogenesis of the disease. Neutralization of IL-12 increased the severity of Tyzzer's disease in mice after 3 days post inoculation [25]. In disseminated forms of the disease and after accessing portal circulation, the bacteria usually disseminate to other organs, particularly the liver and heart, in both mammals and birds $[26,27]$. C. piliforme rarely disseminates into the brain of gerbils and captive birds $[27,28]$.

The aim of this communication is to record a previously unreported dual infection of AEEC and Tyzzer's disease in hamsters and establish a pathogen causal relationship based on the gross findings, histopathologic lesions and molecular testing by PCR.

Clinical disease: Three weanlings (numbered 1 to 3 ) were submitted for necropsy including 2 weanlings that were euthanized and another weanling died unexpectedly after arrival at the pet store. The gastrointestinal tract of all three weanlings 
was thin-walled, variably congested and distended with excessive amounts of turbid, yellowish-green fluid contents particularly the ileum and cecum. The liver and heart from one weanling (\#1) was studded with pinpoint white foci throughout the hepatic and cardiac parenchyma.

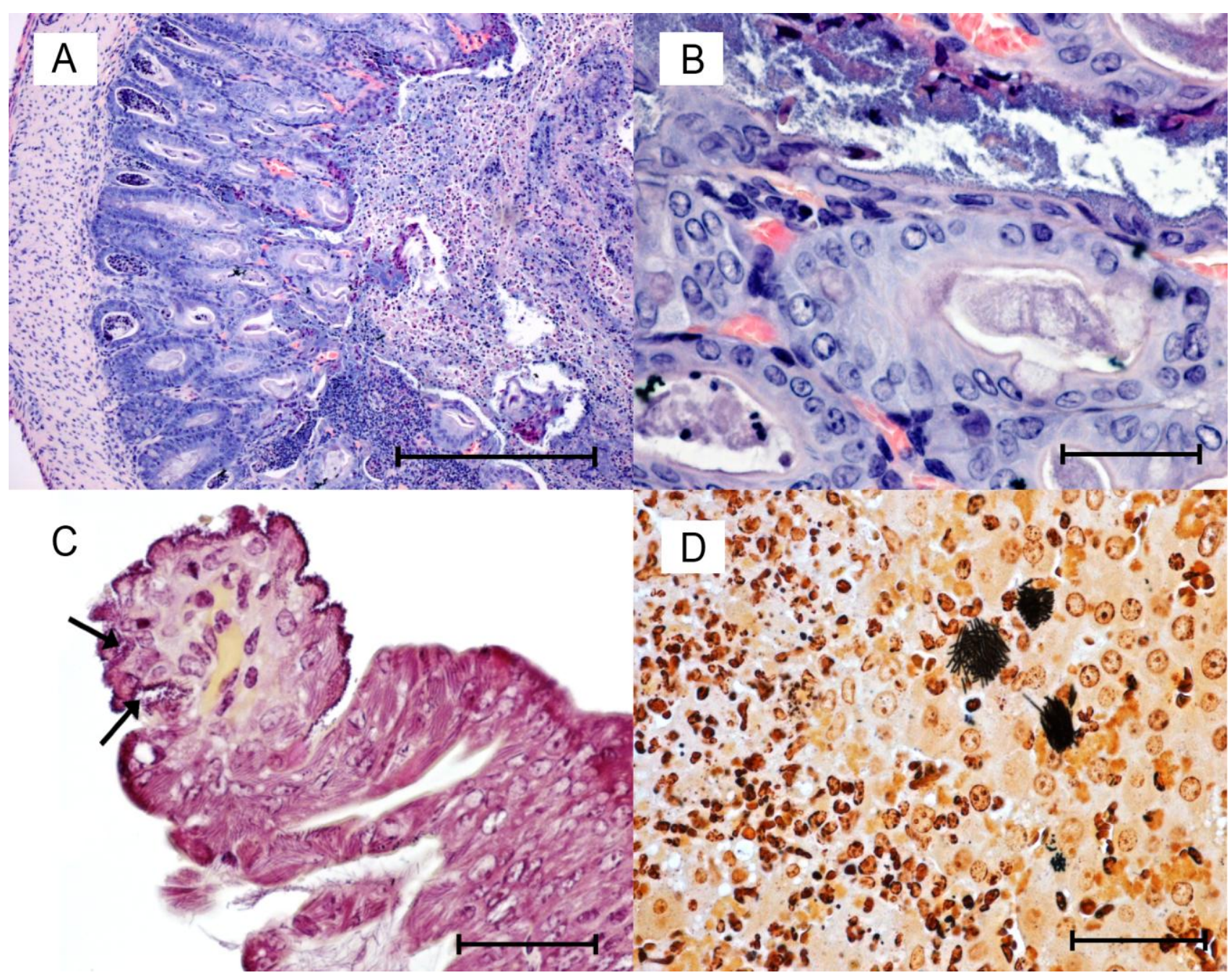

Figure 1 (A): lleum, animal \#1: Mucosa is markedly eroded with multifocal crypt necrosis and efflux of numerous intact and degenerate neutrophils into the lumen. $\mathrm{H} \& \mathrm{E}$. Bar = $200 \mu \mathrm{m}$. (B): lleum, animal \#1; Ragged villous surface is colonized by numerous plump bacilli scalloping the apical surface of enterocytes. $\mathrm{H} \& \mathrm{E}$ Bar $=100 \mu \mathrm{m}$. (C): Atrophic ileal villus is lined by colonies of plump bacilli (arrows) scalloping luminal surface of enterocytes, which also contain gram negative filamentous bacilli of $C$. piliforme in their cytoplasm. Gram stain. Bar $=100 \mu \mathrm{m}$. (D): Liver, weanling No. 1: A locally extensive necrotizing hepatitis comprising karyorrhectic debris, hepatocyte loss and infiltration of necrotic parenchyma by moderate numbers of macrophages and scattered crisscrossing filamentous bacilli highlighted by silver stain. Warthin-Starry stain. Bar $=100 \mu \mathrm{m}$.

Gross and microscopic findings: All tissues were fixed in $10 \%$ buffered formalin and routinely processed to obtain $4-\mu \mathrm{m}$ thick sections for hematoxylin and eosin staining. Intestines from all three weanlings showed multifocally extensive, erosive-toulcerative enterotyphlocolitis. The ileal villi, as well as colonic and cecal mucosae were ragged and markedly scalloped or partially obliterated by abundant cellular debris and massive infiltration of intact and degenerate neutrophils. Epithelial cells lining atrophic villi and on the ileo-cecal-colonic mucosal surface were short, rounded up or exfoliating in small clumps amongst luminal 
aggregates of numerous neutrophils. Many crypts in the most affected areas were moderately ectatic and filled by detached epithelial cells and degenerate leukocytes (Figure 1A). Many other crypts were hyperplastic and were lined by epithelial cells with intensely basophilic cytoplasm and many mitotic figures. In most affected areas, plump, short bacilli were attaching to, scalloping and effacing the apical surface of enterocytes (Figure 1B). Multifocally, these short bacilli were intermixed with "stacks" of faintly staining, Gram negative, intracellular filamentous bacilli consistent with $C$. piliforme (Figure $1 \mathrm{C}$ ). Foci of bacterial adhesion of plump bacilli were patchy in distribution in the distal ileum where bacteria were found on the upper third of ileal villi with no evidence of co-infection by filamentous rods. The liver of one weanling (\#1) had severe, multifocally extensive, necrotizing hepatitis and milder myocarditis with intralesional bacilli consistent with C. piliforme. Approximately $30 \%$ of the normal architecture of the hepatic parenchyma was obliterated by coalescing areas of lytic to coagulative necrosis characterized by hepatocyte loss and replacement by eosinophilic cellular and karyorrhectic debris. Necrotic lesions were intermixed with small to moderate numbers of macrophages or neutrophils especially at the periphery of the necrotic parenchyma. Hepatocytes at the periphery of these necrotic foci were swollen and have pale, vacuolated cytoplasm or else were shrunken with hypereosinophilic cytoplasm and exhibited variable karyopyknosis to karyorrhexis. Silver stain highlighted "haystacks" of crisscrossing bundles or parallel filamentous bacterial rods in cytoplasm of hepatocytes at margins of the necrotic foci (Figure 1D). The heart showed mild multifocal necrotizing myocarditis containing very few organisms.

Diagnosis: No viruses were detected in the feces in any of the 3 animals by direct electron microscopy.

Heavy growth of $E$. coli was obtained from the intestines of the 3 weanlings on MacConkey and blood agar plates under aerobic conditions. No significant bacteria were isolated from the liver (Proteus spp.) and heart of weanling \#1.

Clostridium difficile toxin neutralization test was negative. Fecal cultures were negative for other significant bacteria, particularly Salmonella and Campylobacter spp.

Genomic DNA was extracted using a commercial minikit ${ }^{a}$ from fresh intestines and feces from the three weanlings and fresh liver from weanling \#1 were subjected to PCR amplification by a known primer set specific to $C$. piliforme [29] and a known primer set specific to AEEC [4]. The PCR amplification of $C$. piliforme was performed using commercial kit ${ }^{\mathrm{b}}$ with the following thermocycling conditions: $94^{\circ} \mathrm{C}$ for 5 minutes, 40 cycles of $98^{\circ} \mathrm{C}-10$ seconds, $55^{\circ} \mathrm{C}-30$ seconds, and $72^{\circ} \mathrm{C}-1 \mathrm{~min}$, and final extension at $72^{\circ} \mathrm{C}$ for 5 minutes. Forward primer 5'ACCATTGACAGCCTACGTAA-3' and reverse primer 5' GTCTCGCTTCACTTTGTTGTA-3' was used to amplify the 270 base pair (bp) product of the 16rRNA gene of $C$. piliforme, and was confirmed by sequencing. The NCBI BLAST ${ }^{20}$ (http://www.ncbi.nlm.nih.gov/blast/Blast.cgi) revealed $98 \%$ sequence homology with $C$. piliforme. PCR products of the expected sizes were consistently amplified in all 3 clostridiuminfected hamsters (Figure 2).

The PCR amplification of AEEC was performed using commercial $\mathrm{kit}^{\mathrm{c}}$ with the following thermocycling conditions : $95^{\circ} \mathrm{C}-10$ minutes, 40 cycles of $94^{\circ} \mathrm{C}-30$ seconds, $50^{\circ} \mathrm{C}-45$ seconds, $70^{\circ} \mathrm{C}-1.5$ minutes, final extension at $70^{\circ} \mathrm{C}-10$ minutes. Oligonucleotide set: Forward 5'ATTCCGTTTTAATGGCTATCT-3' and Reverse 5'AATCTTCTGCGTACTGTGTTCA-3' was used to amplify a $425 \mathrm{bp}$ region on the eaeA chromosomal gene of $\mathrm{AEEC}$. The eaeA gene was detected in all the samples collected from the weanlings including fresh feces and pure culture of $E$. coli isolated from the intestines (Figure 3).

All PCR products were electrophoresed on a $1.5 \%$ agarose gel and were visualized by staining with GelRed ${ }^{d}$ stain. 


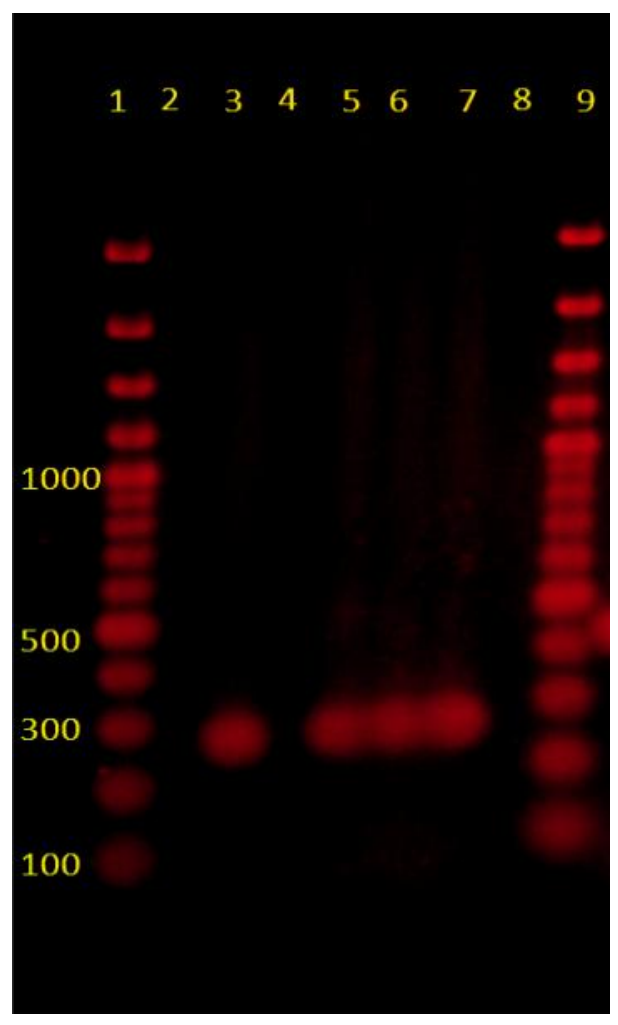

Figure 2. Electrophoretic separation of PCR products from C. piliforme PCR.

Lanes: \#1,9: 100 bp ladder; \#2,8: blank; \#3: positive control; \#4: negative control; \#5: intestine hamster-1; \#6: intestine hamster-2; \#7: intestine hamster-3.

\section{Discussion}

The current report clearly demonstrated that heavy colonization of the small and large intestines of three hamster weanlings by enteropathogenic bacteria and co-infection with $C$. piliforme resulted in a severe enteric disease similar to that described in the early reports of dual infections [1,2].

Pathologic lesions and molecular confirmation of the identity of the causative bacteria establish AEEC as an important cause of diarrhea, which should be included in the differential lists of enteric pathogens in the hamsters. Other possible causes of natural infections characterized by diarrhea in the hamster include Salmonella typhimurium, Campylobacter jejuni, Lawsonia intracellularis, and Clostridium difficile [30,31]. Necrotizing enterohepatitis in hamsters, on the other hand, can be precipitated by Francisella tularensis, Yersinia pestis, $Y$. pseudotuberculosis, $Y$. enterocolitica and C. piliforme, which produce similar pathologic lesions in rodents and lagomorphs $[20,32,33]$. Contact with sick animals or contaminated bedding is

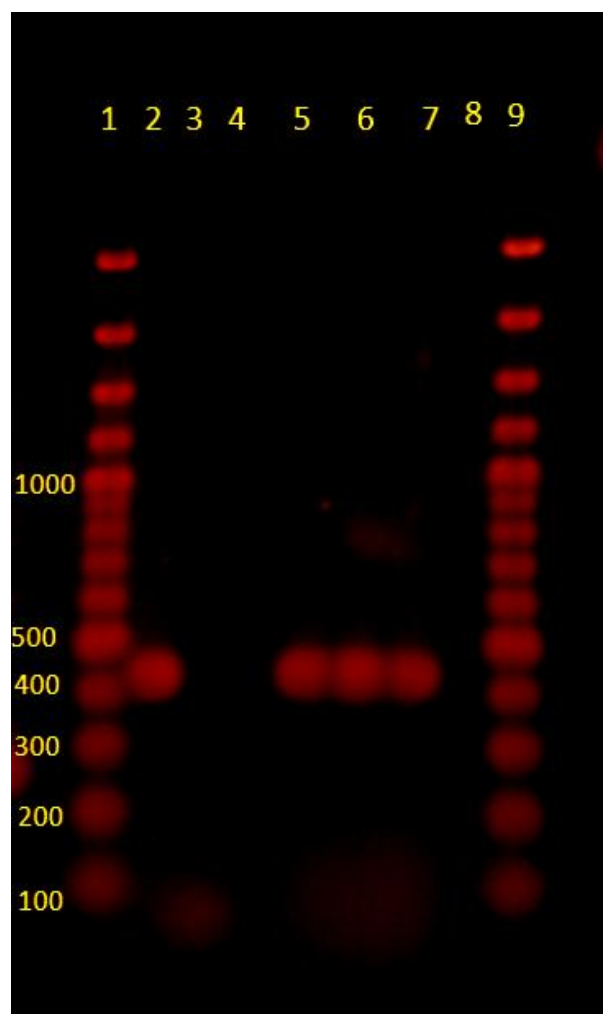

Figure 3. Electrophoretic separation of PCR products from AEEC PCR.

Lanes: \#1,9: 100 bp ladder; \#4,8: blank; \#2: positive control; \#3: negative control; \#5: intestine hamster-1; \#6: intestine hamster-2; \#7: intestine hamster-3.

the most likely source of infection of hamsters in the current report, as has been established in mice [22].

In naturally infected animals, as in the weaned hamsters in the current report, areas showed evidence of mucosal damage where AEEC were the only bacteria colonizing atrophic or hyperplastic ileal villi precludes the possibility that AEEC colonization was just an incidental finding. The more efflux of neutrophils into the lumen of the intestines plus the deeper and more widespread necrotizing lesions attests to the pathogenicity of AEEC in hamsters $[1,11,30]$.

Similar lesions were reported to occur naturally in weaned pigs. The authors, however, were unable to induce similar lesions in older conventional pigs. Moreover, diseases resulting from infection with $A E E C$, such as hemolytic syndrome and hemorrhagic colitis or by related murine A/E Citrobacter rodentium in vivo were most often observed in younger animals or older individuals with an immature or compromised immune status $[5,13,34]$. 
The findings in this report indicates that the primary target of Tyzzer's disease in hamsters is the intestines, particularly the ileum, as only one animal developed disseminated hepatic and cardiac Tyzzer's lesions similar to other mammals and birds $[26,27]$. Diagnosis of Tyzzer's disease in hamsters, similar to other wild and laboratory animal species, can be established upon finding the characteristic necrotizing enterohepatic lesions, intralesional silver-stained filamentous rods and PCR amplification $[20,29,35]$. Caution, however, should be practiced when interpreting the PCR results using feces, as with other bacteria, $C$. piliforme is phylogentically similar to other Clostridia species

\section{References}

1. Amend NK, Lowffler DG, Ward BC, Van Hoosier GL Jr (1976) Transmission of enteritis in the Syrian hamster. Lab Anim 26: 566-572.

2. Dillehay DL, Paul KS, Boosinger TR, Fox JG (1994) Enetrocolitis associated with Escherichia coli and Campylobacter like organisms in a hamster (Mesocricetus auratus) colony. Lab Anim Sci 44: 12-16.

3. Frisk CS, Wagner JE, Owens DR (1978) Enteropathogenicity of Escherichia coli isolated from hamsters (Mesocricetus auratus) with hamster enteritis. Inf and Immun 20: 319-320.

4. Frankel G, Phillips AD, Rosenshine I, Dougan G, Kaper JB, et al. (1998) Enteropathogenic and enterohemorrhagic Escherichia coli more subversive elements. Mol Microbiol 30: 911-921.

5. Girard F, Oswlad IP, Taranu I, Helie P, Applyard GD, et al. (2005) Host immune status influences the development of attaching and effacing lesions in weaned pigs. Infec Immun 73: 5514-5523.

6. Moon HW, Isaacson RE, Pohlenz J (1979) Mechanism of association of enteropathogenic Escherichia. Coli with intestinal epithelium. Am J clin Nut 32: 119-127.

7. Nicholls L, Grant TH, Robins-Browne RM (2000) Identification of novel genetic locus that is required for in vitro adhesion of clinical isolate of enterohemorrhagic Escherichia coli to epithelial cells. Molec Microbiol 35: 275 $\underline{288}$.

8. Knutton S, Baldwin T, Williams PH, McNiesh AS (1989) Actin accumulation at sites of bacterial adhesion to tissue culture cells: basis of a new diagnostic test for enteropathogenic and enterohemorrhagic Escherichia coli. Infec Immun 57: $\underline{1290-1298 .}$.

9. Luck SN, Bennett-Wood V, Poon R, Robins-Browne RM, Hartland EL (2005) Invasion of epithelial cells by locus of enterocyte effacement-negative enterohemorrhagic Escherichia coli. Infec Immun 73: 3063-3071.

10. McDaniel TK, Jarvis KG, Donneberg MS, Kaper JB (1995) A genetic locus of
$[20,36]$. In juvenile hamsters, Tyzzer's disease is most commonly associated with a primary stressor, as it is shown to occur secondary to immunocompromised status resulting from nutritional imbalances, overcrowding and other environmental stressors, infectious causes or treatment with corticosteroids $[26,37]$.

In conclusion, the current report establishes $A E E C$ as a causative agent of diarrhea in the hamsters, which are susceptible to dual infection with enteropathogenic E.coli and C. piliforme at weanling or very young age.

enterocyte effacement conserved among diverse enterobacterial pathogens. Proc Natl Acad Sci USA 92: 1664-1668.

11. Jerse AE, Gicquelais KG, Kaper JB (1991) Plasmid and chromosomal elements involved in the pathogenesis of attaching and effacing Escherichia coli. Infect Immun 59: 3869-3875.

12. Jerse, Kaper JB (1991) The eae gene of enteropathogenic Escherichia coli encodes a 94-kilodalton membrane protein, the expression of which is influenced by the EAF plasmid. Infect. Immun. 59: 4302-4309.

13. Zhu C, Harel J, Jacques M, Desautels C, Donnenberg MS, et al.(1994) Virulence properties and attaching effacing activity of Escherichia coli 045 from swine post-weaning diarrhea. Infect Immun 62: 4153-4159.

14. Bieber D, Ramer SW, Wu CY, Murray WJ, Tobe T, et al. (1998) Type 4 pili, transient bacterial aggregates, and virulence of enteropathogenic Escherichia coli. Science 280: 2114-2118.

15. Giron JA, Ho AS, Schoolnik GK (1991) An inducible bundle-forming pilus of enteropathogenic Escherichia Coli. Science 254: 710-713.

16. Nataro JP, Kaper JB (1998) Diarrheagenic Escherichia coli. Clin Microbiol Rev 11: 142-201.

17. Stein MA, Mathers DA, Yan H, Baimbridge KG, Finlay BB (1996) Enteropathogenic Escherichia coli markedly decrease the resting membrane potential of Caco-2 and HeLa human epithelial cells. Infect Immun. 64: 4820$\underline{4825}$.

18. Tzipori, S, Gibson R, Montanaro J (1989) Nature and distribution of mucosal lesions associated with enteropathogenic and enterohemorrhagic Escherichia coli in piglets and the role of plasmid-mediated factors. Infect.Immun. 57: 1142-1150.

19. Vanmaele RP, Finlay MC, Armstrong GD (1995) Effect of enteropathogenic Escherichia coli on adherent properties of Chinese hamster ovary cells. Infec and Immun 36: 191-198. 
20. Feldman SH, Kivand A, Sidelin M, Reiske HR (2006) Ribosomal RNA sequences of Clostridium piliforme isolated from rodent and rabbit: Re-examining the phylogeny of the Tyzzer's disease agent and development of a diagnostic polymerase chain reaction assay. J Am Assoc Lab Anim Sci 45: 65-73.

21. Ikegami T, Shirota K, Une Y, Nomura Y, Wada Y, et al. (1999) Naturally occurring Tyzzer's disease in a calf. Vet Pathol 36: 253-255.

22. Rights FL, Jackson EB, Technician C, Smadel JE (1947) Observations on Tyzzer's disease in mice. Am J Pathol 23:627-635.

23. Zook BC, Huang K, Rhorer RG (1997) Tyzzer's disease in Syrian hamsters. J Am Vet Med Assoc 171: 833-836.

24. Karstad L, Lusis P, Wright D (1971) Tyzzer's disease in muskrats. J Wild Dis 7:9699.

25. Van Andel RA, Hook RR Jr, Franklin CL, Besch-Williford CL, Riley LK (1998) Interleukin-12 has a role in mediating resistance of murine strains to Tyzzer's disease. Infec and Immun 66: 4942-4946.

26. Ikegami T, Shirota K, Goto K, Takakura A, Itoh T, et al. (1999) Enetrocolitis associated with dual infection by Clostridium piliforme and feline panleukopenia virus in three kittens. Vet Pathol 36: 613-615.

27. Raymond JT, Topham K, Shirota K, Garner MM (2001) Tyzzer's disease in a neonatal rainbow lorikeet (Trichoglossus haematodus). Vet Pathol 38: 326-327.

28. Veazey RS 2nd, Paulsen DB, Schaeffer DO (1992) Encephalitis in gerbils due to naturally occurring infection with Bacillus piliformis (Tyzzer's disease). Lab Anim Sci 42:516-518.

29. Brooks JW, Whary MT, Hattel AL, Shaw DP, Ge Z, et al. (2006) Clostridium piliforme infection in two farm-raised deer fawns (Odocoileus virigianus) and association with copper toxicosis. Vet Pathol 43:765-768.
30. Fox JG, Zanotti S, Jordan HV, Murphy JC (1986) Colonization of Syrian hamsters with streptomycin resistant Campylobacter jejuni. Lab Anim Sci 36: 28-31.

31. Innes JRM, Wilson C, Ross MA (1956) Epizootic Salmonella enteritidis infection causing septic pulmonary phlebothrombosis in hamsters. J Infect Dis 98: 133141.

32. Blankenship-Paris TL, Walton BJ, Hayes YO, Chang J (1995) Clostridium difficile infection in hamsters fed an atherogenic diet. Vet Path 32: 269-273.

33. Wobeser G, Campbell GD, Dallaire A, McBurney S (2009) Tularemia, plague, yersiniosis and Tyzzer's disease in wild rodents and lagomorphs in Canada: A review. Can Vet J 50: 1251-1256.

34. Vallence BA, Deng $W$, Knodler LA, Finlay BB (2002) Mice lacking $T$ and $B$ lymphocytes develop transient colitis and crypt hyperplasia yet suffer impaired bacterial clearance during Citrobacter rodentium infection. Infec Immun70: 2070-2081.

35. Franklin CL, Motzel SL, Besch-Williford CL, Hook RR Jr, Riley LK (1994) Tyzzer's infection: host specificity of Clostridium piliforme isolates. Lab Anim Sci 44: 568-572.

36. Cooper DM, Swanson DL, Gebhart CJ (1997) Diagnosis of proliferative enteritis in frozen and formalin-fixed, paraffin-embedded tissues from a hamster, horse, deer and ostrich using a Lawsonia intracellularis-specific multiplex PCR assay. Vet Microbiol 54: 47-62.

37. Fosgate GT, Hird DW, Read DH, Walker RL (2002) Risk factors for Clostridium piliforme infection in foals. J Am Vet Med Assoc 220: 785-790.

38. Mete A, Eigenheer A, Goodnight A, Woods L (2011) Clostridium piliforme encephalitis in a weaver bird (Ploceus castaneiceps). J Vet Diagn Invest 23: 1240-1242. 